\title{
MHD Stagnation-Point Flow over a Stretching/Shrinking Sheet in a Micropolar Fluid with a Slip Boundary
}

(Aliran Titik Genangan MHD terhadap Lembaran Meregang/Mengecut dalam Bendalir Mikrokutub dengan Gelinciran Sempadan)

\author{
SITI KHUZAIMAH SOID, ANUAR ISHAK* \& IOAN POP
}

\begin{abstract}
The problem of stagnation point flow over a stretching/shrinking sheet immersed in a micropolar fluid is analyzed numerically. The governing partial differential equations are transformed into a system of ordinary (similarity) differential equation and are then solved numerically using the boundary value problem solver (bvp4c) in Matlab software. The effects of various parameters on the velocity and the angular velocity as well as the skin friction coefficient and the couple stress are shown in tables and graphs. The noticeable results are found that the micropolar and the slip parameters decrease the skin friction coefficient and the couple stress in the existence of magnetic field. Dual solutions appear for certain range of the shrinking strength. A stability analysis is performed to determine which one of the solutions is stable. Practical applications include polymer extrusion, where one deals with stretching of plastic sheets and in metallurgy that involves the cooling of continuous strips.
\end{abstract}

Keywords: Micropolar fluid; stability analysis; stagnation point flow; stretching/shrinking

\section{ABSTRAK}

Masalah aliran titik genangan di atas lembaran meregang/mengecut yang direndam dalam bendalir mikrokutub dianalisis secara berangka. Persamaan menakluk pembezaan separa dijelmakan menjadi sistem persamaan pembezaan biasa (keserupaan) dan kemudian diselesaikan secara berangka menggunakan penyelesai masalah nilai sempadan (bvp4c) dalam perisian Matlab. Kesan pelbagai parameter terhadap profil halaju dan halaju sudut serta pekali geseran kulit dan tegasan kupel ditunjukkan dalam jadual dan graf. Hasil yang ketara didapati bahawa parameter mikrokutub dan gelinciran menurunkan pekali geseran kulit dan tegasan kupel dengan kehadiran medan magnet. Penyelesaian dual diperoleh untuk kekuatan tertentu regangan. Analisis kestabilan dilakukan untuk menentukan penyelesaian mana yang stabil antara dua penyelesaian yang diperoleh ini. Aplikasi praktikal termasuk penyemperitan polimer dengan peregangan lembaran plastik dan metalurgi yang melibatkan penyejukan jalur berterusan.

Kata kunci: Aliran titik genangan; analisis kestabilan; bendalir mikrokutub; meregang/mengecut

\section{INTRODUCTION}

Forced convection flow and heat transfer over a stretching/ shrinking sheet has many practical applications in industries. For example, the thermal processing of sheetlike materials occurs in the production of paper, polymeric sheets, insulating materials, fine-fiber mattes and boundary layer along a liquid film in condensation process (Fisher 1976). This problem may have applications also in polymer technology where one deals with stretching of plastic sheets and in metallurgy that involves the cooling of continuous strips.

The investigation of micropolar fluid flow is originated from the studies of biological molecular machinery, atherogenesis, microcirculation and microfluidics. The idea is based on rotating particles in which this rotation is described by an independent microrotation vector. The theory of micropolar fluids was initiated by Eringen (1966). According to Eringen (1966), the micropolar fluids exhibit micro-rotational motion and spin inertia of particles, thus can support couple stress and distributed body couple. Shearing stress components in these fluids are affected by the vorticity and micro-rotation of the fluid and are no longer symmetric.

There are numerous applications dealing with micropolar fluids including the extrusion of polymer fluids, solidification of liquid crystals, cooling of a metallic plate in a bath, animal bloods, exotic lubricants and colloidal and suspension solutions. These fluids are analog to rigid molecules, magnetic fluids, clouds with dust, muddy fluids, and some biological fluids (Shu \& Lee 2008). There are some important practical applications involved in the predictions of environmental pollution in the ocean and atmosphere, thermal stratification in lakes, as well as development and design of chemical processing equipment (Ishak et al. 2009).

A stagnant point at which the shear stress is zero may occur when a flow impinges on a solid object. The study of stagnation point flow has attracted the interest of 
many researchers because of its applications in industry, including flows over the tips of aircrafts and submarines. Hiemenz (1911) was the first who obtained an exact solution of the steady two-dimensional stagnation point flow over a flat surface.

The axisymmetric stagnation-point flow of a micropolar fluid over a flat plate was studied by Peddieson (1972). He proposed a new boundary condition, motivated by an analogy with phenomenological theories of turbulence. The numerical results appeared to have the characteristics of turbulent shear flows. Ahmadi (1976) studied the micropolar boundary layer flow over a semiinfinite plate, where the theory of micropolar fluid and its application to low concentration suspension flow was discussed. Later, Jena and Mathur (1981) investigated the thermomicropolar fluid past a non-isothermal vertical flat plate. Nazar et al. (2004) studied the micropolar fluid flow over a stretching sheet with a velocity proportional to the distance from the stagnation point.

Later, the problem of stagnation-point flow in a micropolar fluid was extended in numerous ways to include various physical effects and surface heating conditions such as Adegbie et al. (2016), Aman et al. (2013a), Animasaun (2017), Baag et al. (2017), Borreli et al. (2015), Das (2012), Ishak et al. (2010) and Yacob et al. (2011) among others. These authors studied the problems of stagnation point flow in micropolar fluids with no slip effects at the boundary. Lok et al. (2005) studied the steady mixed convection flow of a micropolar fluid near the stagnation point on a vertical surface and solved it numerically using the Keller-box method. They found that with the existence of the micropolar parameter and buoyancy effects led to a decrease in the skin friction coefficient and the rate of heat transfer on the non-slip surface. Ishak et al. (2010) found that the micropolar parameter decreased the skin friction coefficient and this recovery is consistent with that reported by Lok et al. (2005). Moreover, it also reported that the couple stress decreased with the increase of the micropolar parameter.

Even though in general situations, molecules of a fluid adhere to the surface, but, there are some applications where the molecules deviate from it. The no-slip condition declares the fluid is in contact with surface, thus the fluid velocity at the surface is zero. Meanwhile, the slip condition allows the fluid flow to move freely on the surface, thus there is a velocity gradient on the surface. The slip velocity often occur in inhomogeneous fluids, especially slurries, gels, emulsions and foams (Yoshimura \& Prud'homme 1988) and when the plate is coated with special coating such as a thick monolayer of hydrophobic octadecyltrichlorosilane (Tretheway et al. 2002).

Mooney (1931) probably was the pioneer to study the boundary layer flow with partial slip. This original research has been extended by Yoshimura and Prud'homme (1988) and he proposed a new analysis of the Couette geometry and a new analysis for flow between rotating parallel disks in the presence of wall slip. Wang (2003) studied stagnation-point flows with a first-order velocity slip of rarefied gases where exact solutions of the Navier-Stokes equations were derived.

In fact, in some systems such as microfluidic and over certain deformation rate regime the contribution of wall slip to the total flow rate could be substantial and the slip effect has been confirmed experimentally (Meeten 2004; Nair \& Sameen 2015). Many researchers have actively pursued further research in this field for example Aman et al. (2013b), Malvandi et al. (2014) and Sajid et al. (2012). Later, Hafidzuddin et al. (2015) investigated a permeable exponentially stretching/shrinking sheet with generalized slip velocity. They noticed that dual solutions were found for certain ranges of the suction and stretching/shrinking parameters. Recent studies on the flow with slip boundaries include those of Imran et al. (2018), Mat Yasin et al. (2017), Rahmati et al. (2018) and Uddin et al. (2016), among others.

The study of magnetohydrodynamic (MHD) flow and heat transfer of an electrically conducting fluid is of considerable interest in the modern metallurgical and metal-working processes. This study is considered also of great interest due to the effect of the magnetic field on the boundary-layer flow control and on the performance of many systems using electrically conducting fluids. Some of the engineering applications are in MHD generators, plasma studies, nuclear reactor, geothermal energy extractions, and purifications of metal from non-metal enclosures, polymer technology and metallurgy, MHD heat and mass transfer systems and design of MHD power generators (Shercliff 1965).

MHD flow of an incompressible viscous fluid caused by deformation of a plane surface has been studied by several authors such as Chakrabarti and Gupta (1979) who have studied the temperature distribution in the hydromagnetic flow and heat transfer over a stretching sheet, where a closed form of similarity solution was reported. This analysis was then extended by Chiam (1995) to a stretching surface with a power-law velocity distribution and by Ishak (2011) to an exponentially stretching sheet. To obtain similarity solutions, a special form of the magnetic field was introduced. Andersson (1995) reported the exact solution of the Navier-Stokes equations for the magnetohydrodynamic flow past a stretching sheet. Ishak et al. (2008) studied the MHD flow due to a moving extensible sheet that obeys a more general stretching law, where exact analytical solutions were reported for certain special cases. The MHD flow in a micropolar fluid was studied quite recently by Borrelli et al. (2015), while Basir et al. (2017) studied the MHD bionanofluid flow with zero mass flux boundary condition.

The aim of the present paper was to study the MHD stagnation-point flow over a stretching or shrinking sheet immersed in a micropolar fluid with slip effect at the boundary. Magnetic effect in micropolar fluid is important to control the velocity of the fluid in order to obtain a desired product or to achieve a successful process. Since dual solutions are identified when the surface is shrunk for certain ratios (Mat Yasin et al. 2017; Najib et al. 2014; Zaimi et al. 2014), a stability analysis is performed in 
order to determine which solutions is physically reliable. We hope that the results obtained will provide useful information for applications and as a complement to the previous studies.

\section{MATHEMATICAL FORMULATION}

The steady and incompressible micropolar fluid flow over a flat plate with constant density and with no body forces or body couples are written as (Papautsky et al. 1999):

Continuity equation:

$$
\nabla \cdot \mathbf{V}=0
$$

Linear Momentum equation:

$$
(\mathbf{V} . \nabla) \mathbf{V}=\frac{1}{\rho} \nabla p+\left(v+\frac{\kappa}{\rho}\right) \nabla^{2} \mathbf{V}+\frac{\kappa}{\rho} \nabla \times \mathbf{N}
$$

Angular Momentum equation:

$$
(\mathbf{V} . \nabla) \mathbf{N}=-\frac{2 \kappa}{\rho j} \mathbf{N}+\frac{\chi}{\rho j} \nabla^{2} \mathbf{N}+\frac{\kappa}{\rho j} \nabla \times \mathbf{V}
$$

The vector notation $\mathbf{V}$ is the velocity vector; $\mathbf{N}$ is the microrotation velocity vector; $\rho$ is fluid density; $p$ is the thermodynamic pressure; $v$ is kinematic viscosity; $\kappa$ is vortex viscosity; $\chi$ is spin gradient viscosity; and $j$ is micro-inertia per unit mass.

An investigation was carried out on the stagnationpoint flow over a stretching/shrinking sheet immersed in a micropolar fluid as shown in Figure 1, where $x$ and $y$ are the Cartesian coordinates with the $x$ axis measured along the surface of the sheet and the $y$ axis normal to it. The flow takes place in the region $y \geq 0$. It is assumed that the external flow impinging normal to the sheet is assumed to be in the form $U_{\infty}=b x$ and the stretching/shrinking velocity is $U_{w}=a x$, where $a$ and $b$ are constants with $b$ $>0$. The values of $a$ can be positive or negative which represent the stretching or shrinking cases, respectively. It is also assumed that a constant magnetic field $B_{0}$ is applied normal to the surface of the sheet oriented in the $y$-direction. The induced magnetic field is neglected, as it is assumed small.

Under these assumptions and applying the boundary layer approximations to (1) - (3), the MHD two-dimensional boundary layer equations of the conservative of mass, momentum and angular momentum are given by (Ishak et al. 2010),

$$
\frac{\partial u}{\partial x}+\frac{\partial v}{\partial y}=0
$$

$$
u \frac{\partial u}{\partial x}+v \frac{\partial u}{\partial y}=U_{\infty} \frac{d U_{\infty}}{d x}+\left(v+\frac{\kappa}{\rho}\right) \frac{\partial^{2} u}{\partial y^{2}}+\frac{\kappa}{\rho} \frac{\partial N}{\partial y}-\frac{\sigma B_{0}^{2}}{\rho}\left(u-U_{\infty}\right)
$$

$$
u \frac{\partial N}{\partial x}+v \frac{\partial N}{\partial y}=\frac{\chi}{\rho j} \frac{\partial^{2} N}{\partial y^{2}}-\frac{\kappa}{\rho j}\left(2 N+\frac{\partial u}{\partial y}\right)
$$

subjected to the boundary conditions (Abbas et al. 2018; Das 2012)

$$
\begin{aligned}
& u=U_{w}(x)+L \frac{\partial u}{\partial y}, \quad v=0, \quad N=-m \frac{\partial u}{\partial y} \text { at } y=0 \\
& u \rightarrow U_{\infty}(x), N \rightarrow 0 \text { as } y \rightarrow \infty .
\end{aligned}
$$

In these equations, $u$ and $v$ are the velocity components along the $x$ and $y$-axes, respectively; $N$ is the microrotation or angular velocity which the direction of rotation is normal to the $x-y$ plane; $v$ is the kinematic viscosity; $L$ is the slip length factor; $\sigma$ is the electrical conductivity of the fluid and $m$ is a constant such that $0 \leq m \leq 1$. There are three values of parameter $m$ that usually stated in the literature; which are $m=0, m=1 / 2$ and $m=1$. The value $m=0$ indicates a strong concentration which implies the irrotation of the microelements close to the wall, $m=1 / 2$ represents the weak concentrations of microelements and $m=1$ illustrates the turbulent boundary layers (Peddieson 1972). According to Ahmadi (1976), $\chi$ can be defined as $\chi=(\mu+\kappa / 2) \mathrm{j}=\mu(1+K / 2) j$ where $\mu$ is the dynamic viscosity; $K=\kappa / \mu$ is the micropolar parameter; and we take $j=v / b$ as a reference length which gives relationship between the coeficients of viscosity and micro-inertia. It should be mentioned that the momentum (5) is based on

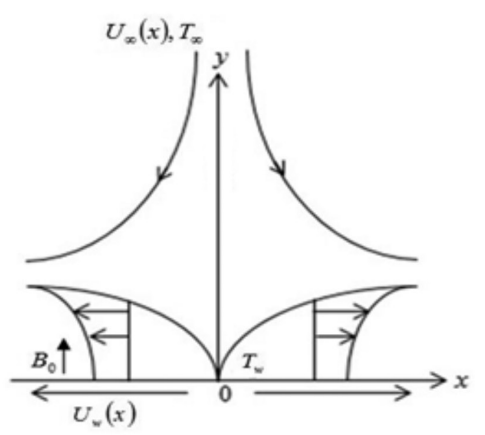

(a) Stretching sheet

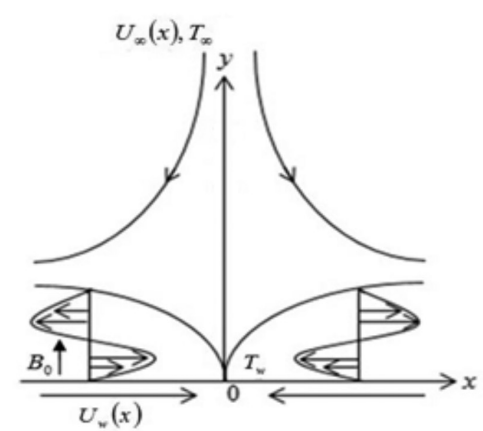

(b) Shrinking sheet

FIGURE 1. Physical model and coordinate system 
the linearization of the Lorentz force, which occurs in the limit of small magnetic Reynolds number. This model is a suitable approximation for the Lorentz force in the boundary layer which has moving boundary conditions.

Equations (4)-(6) along with the boundary conditions (7) can be expressed in a simpler form by introducing the following similarity transformation:

$$
\eta=\left(\frac{U_{\infty}}{v x}\right)^{1 / 2} y, \quad \psi=\left(v x U_{\infty}\right)^{1 / 2} f(\eta), \quad N=U_{\infty}\left(\frac{U_{\infty}}{v x}\right)^{1 / 2} h(\eta)
$$

where $\eta$ is the similarity variable; and $\psi$ is the stream function defined as $u=\partial \psi / \partial y$ and $\mathrm{v}=-\partial \psi / \partial x$ which identically satisfies the conservative of mass equation (4). The transformed linear momentum (5) and angular momentum (6), respectively, reduce to

$$
\begin{aligned}
& (1+K) f^{\prime \prime \prime}+f f^{\prime \prime}+1-f^{2}+K h^{\prime}+M^{2}\left(1-f^{\prime}\right)=0 \\
& \left(1+\frac{K}{2}\right) h^{\prime \prime}+f h^{\prime}-f^{\prime} h-K\left(2 h+f^{\prime \prime}\right)=0
\end{aligned}
$$

The prime indicates differentiation with respect to $\eta$ and $M=B_{0}\left(\frac{\sigma}{b \rho}\right)^{1 / 2}$ represents the Hartmann number or known as the magnetic parameter. The corresponding boundary conditions now become

$$
\begin{aligned}
& f(0)=0, f^{\prime}(0)=\varepsilon+\lambda f^{\prime \prime}(0), h(0)=-m f^{\prime \prime}(0), \\
& f^{\prime}(\eta) \rightarrow 1 . h(\eta) \rightarrow 0 \text { as } \eta \rightarrow \infty,
\end{aligned}
$$

where $\varepsilon=b / a$ is the velocity ratio parameter and $M=B_{0}\left(\frac{\sigma}{b \rho}\right)^{1 / 2}$ is the slip parameter.

The physical quantities of interest are the skin friction coefficient $C$ and the local couple stress $M_{x}$, which are defined as (Jena \& Mathur 1981),

$$
C_{f}=\frac{\tau_{w}}{\rho U_{\infty}^{2}}, \quad M_{x}=\frac{v M_{w}}{x U_{\infty}^{2}}
$$

where the surface shear stress $\tau_{w}$ and the surface couple stress $M_{w}$ are given by

$$
\tau_{w}=\left[(\mu+\kappa) \frac{\partial u}{\partial y}+\kappa N\right]_{y=0}, \quad M_{w}=\left[\frac{v}{b} \frac{\partial N}{\partial y}\right]_{y=0}
$$

Then, we obtain the reduced skin friction coefficient and the reduced local couple stress

$$
C_{f} \operatorname{Re}_{x}^{1 / 2}=[1+(1-m) K] f^{\prime \prime}(0), \quad M_{x} \operatorname{Re}_{x}=h^{\prime}(0),
$$

where $\operatorname{Re}_{x}=U_{\infty} x / v$ is the local Reynolds number.

\section{STABILITY ANALYSIS}

Since dual solutions are possible for a certain range of parameter, it is worth to study the stability of these solutions, to determine which one of the solutions is stable and which one is unstable. To do this, we follow the works of Merkin (1985) and Weidman (2016) by considering the unsteady problem. Equation (4) is unchanged, while equations (5) and (6) become

$$
\begin{aligned}
& \frac{\partial u}{\partial t}+u \frac{\partial u}{\partial x}+v \frac{\partial u}{\partial y}=\frac{\partial U_{\infty}}{\partial t}+U_{\infty} \frac{d U_{\infty}}{d x}+\left(v+\frac{\kappa}{\rho}\right) \\
& \frac{\partial^{2} u}{\partial y^{2}}+\frac{\kappa}{\rho} \frac{\partial N}{\partial y}-\frac{\sigma B_{0}{ }^{2}}{\rho}\left(u-U_{\infty}\right) \\
& \psi=\left(v x U_{\infty}\right)^{1 / 2} f(\eta, \tau), \quad N=U_{\infty}\left(\frac{U_{\infty}}{v x}\right)^{1 / 2} h(\eta, \tau), \quad \tau=b t
\end{aligned}
$$

where $t$ is time.

Following Merkin (1985) and Weidman (2016) the new dimensionless variables guided from equation (8) are as follows:

$$
\psi=\left(v \times U_{\infty}\right)^{1 / 2} f(\eta, \tau), \quad N=U_{\infty}\left(\frac{U_{\infty}}{v x}\right)^{1 / 2} h(\eta, \tau), \quad \tau=b t,
$$

where $\tau$ is the dimensionless time. Substituting equation (17) into (15) and (16) yield

$$
\begin{aligned}
& \left(1+\frac{K}{2}\right) \frac{\partial^{2} h}{\partial \eta^{2}}+f \frac{\partial h}{\partial \eta}-\frac{\partial f}{\partial \eta} h-K\left(2 h+\frac{\partial^{2} f}{\partial \eta^{2}}\right)-\frac{\partial h}{\partial \tau}=0 \\
& \left(1+\frac{K}{2}\right) \frac{\partial^{2} h}{\partial \eta^{2}}+f \frac{\partial h}{\partial \eta}-\frac{\partial f}{\partial \eta} h-K\left(2 h+\frac{\partial^{2} f}{\partial \eta^{2}}\right)-\frac{\partial h}{\partial \tau}=0
\end{aligned}
$$

subjected to the boundary conditions

$$
\begin{aligned}
& f(0, \tau)=0, \frac{\partial f}{\partial \eta}(0, \tau)=\varepsilon+\lambda \frac{\partial^{2} f}{\partial \eta^{2}}(0, \tau), \\
& h(0, \tau)=\frac{\partial^{2} f}{\partial \eta^{2}}(0, \tau) \\
& \frac{\partial f}{\partial \eta}(0, \tau) \rightarrow 1, h(\eta, \tau) \rightarrow 0 \text { as } \eta \rightarrow \infty .
\end{aligned}
$$

In order to test the stability of the steady flow solution $f(\eta)=f_{0}(\eta)$ and $h(\eta)=f_{0}(\eta)$ satisfying the boundary-value problem (18)-(20), we write (Merkin 1985),

$$
\begin{aligned}
& f(\eta, \tau)=f_{0}(\eta)+e^{-\gamma \tau} F(\eta) \\
& h(\eta, \tau)=h_{0}(\eta)+e^{-\gamma \tau} G(\eta)
\end{aligned}
$$


where $\gamma$ is an unknown eigenvalue; and $F(\eta)$ and $G(\eta)$ are small relative to $f_{0}(\eta)$ and $h_{0}(\eta)$. There are infinite set of eigenvalue $\gamma$ by solving equations (18)-(20). Negative eigenvalue indicates an initial growth of disturbances which embarks the unstable flow. Meanwhile, positive eigenvalue shows an initial decay, which results in stable flow. We obtain the following linearized system after substituting (21) into (18) and (19):

$$
\begin{aligned}
& (1+K) F^{\prime \prime \prime}+f_{0} F^{\prime \prime}+f_{0}^{\prime \prime} F-\left(2 f_{0}^{\prime}+M-\gamma\right) F^{\prime}+K G^{\prime}=0 \\
& \left(1+\frac{K}{2}\right) G^{\prime \prime}+f_{0} G^{\prime}+F h_{0}^{\prime}-f_{0}^{\prime} G-F^{\prime} h_{0}-2 K G-K F^{\prime \prime}+\gamma G=0
\end{aligned}
$$

along with the boundary conditions

$$
\begin{aligned}
& F(0)=0, \quad F^{\prime}(0)=\lambda F^{\prime \prime}(0), \quad G(0)=-m F^{\prime \prime}(0), \\
& F^{\prime}(\eta) \rightarrow 0, G(\eta) \rightarrow 0, \text { as } \eta \rightarrow \infty .
\end{aligned}
$$

It should be stated that for particular values of $K, M$, $\lambda, \gamma, \varepsilon$ and $m$, the stability of the corresponding steady equations (9) and (10) with the boundary conditions (11) are determined by the eigenvalue $\gamma$. Based on (21), there is an initial decay of disturbance if $\gamma$ is positive which results in a stable flow. In contrast, negative values of $\gamma$ cause the initial growth of disturbance which indicates an unstable flow.

\section{RESULTS AND DISCUSSION}

An analysis of the behaviors of the linear and angular velocities of a micropolar fluid flow over a stretching/ shrinking sheet is carried out. Several values are considered which are the micropolar parameter $K$, slip parameter $\lambda$ and stretching/shrinking parameter $\varepsilon$, while the other parameters, which are material parameter $m$ and magnetic parameter $M$, are fixed to $m=0.5$ and $M=1$. A numerical code is constructed for the equations (9) and (10) subjected to the boundary conditions (11). The numerical solutions are obtained using a boundary value problem solver bvp4c in Matlab. In order to assess the accuracy of the present code, the results are compared with those of Ishak et al. (2010) and Wang (2008) for the case when the micropolar, material, slip and magnetic parameters are absent, as presented in Tables 1 and 2, which show a good agreement. Thus, it can be concluded that the present code is reliable to generate the correct results.

The variations of the surface shear stress $f^{\prime \prime}(0)$ and the couple stress $h^{\prime}(0)$ against the stretching/shrinking parameter $\varepsilon$ are illustrated in Figures 2-7 for various values of the micropolar parameter $K$, slip parameter $\lambda$, stretching/shrinking parameter $\varepsilon$ and magnetic parameter $M$. As can be seen from these figures, the values of $f^{\prime \prime}(0)$ are always positive for $\varepsilon<1$ up to some critical values of $\varepsilon_{c}$. Physically, the positive sign implies that the fluid exerts a drag force on the solid surface, while a negative sign indicates otherwise as shown in these figures for $\varepsilon>1$. Meanwhile, when $\varepsilon=1$, the fluid and the solid surface move with the same velocity, which implies no friction at the fluid-solid interface, i.e. $f^{\prime \prime}(0)=0$.

The presented results in Figure 2 illustrate an increase in the value of the micropolar parameter $K$ leads to a decrease of the skin friction coefficient $f^{\prime \prime}(0)$, in absolute sense, for both shrinking and stretching cases. The decrease of $f^{\prime \prime}(0)$ with increasing $K$ shows that the surface shear stress of a Newtonian fluid $(K \neq 0)$ is higher than that of the micropolar fluid . This is due to the micro-rotation effect that decreases the friction at the fluid-solid interface. It is also noticed that the range of $\varepsilon$ for which the solution exists is wider than that reported by Ishak et al. (2010) due to the

TABLE 1 . Values of $f^{\prime \prime}(0)$ for the stretching sheet when $K=0, \lambda=0, M=0$ and $m=0$

\begin{tabular}{cccc}
\hline$\varepsilon$ & Wang (2008) & Ishak et al. (2010) & Present results \\
\hline 0 & 1.232588 & 1.232588 & 1.232588 \\
0.5 & 0.713300 & 0.713295 & 0.713295 \\
1 & 0 & 0 & 0 \\
5 & -10.264750 & -10.264749 & -10.264749 \\
\hline
\end{tabular}

TABLE 2. Values of $f^{\prime \prime}(0)$ for the shrinking sheet when $K=0, \lambda=0, M=0$ and $m=0$

\begin{tabular}{lccccc}
\hline \multirow{2}{*}{$\varepsilon$} & \multicolumn{2}{c}{ Ishak et al. (2010) } & & \multicolumn{2}{c}{ Present results } \\
\cline { 2 - 3 } \cline { 5 - 6 } & First solution & Second solution & & First solution & Second solution \\
\hline-0.5 & 1.495670 & & & 1.495670 & \\
-0.25 & 1.489298 & & & 1.489298 & 0 \\
-1 & 1.328817 & 0.049229 & & 1.328817 & 0.049229 \\
-1.1 & 1.186681 & 0.116702 & & 1.086680 & 0.116702 \\
-1.15 & 1.082231 & 0.233650 & & 0.932474 & 0.233650 \\
-1.2 & 0.932474 & & & & \\
\hline
\end{tabular}




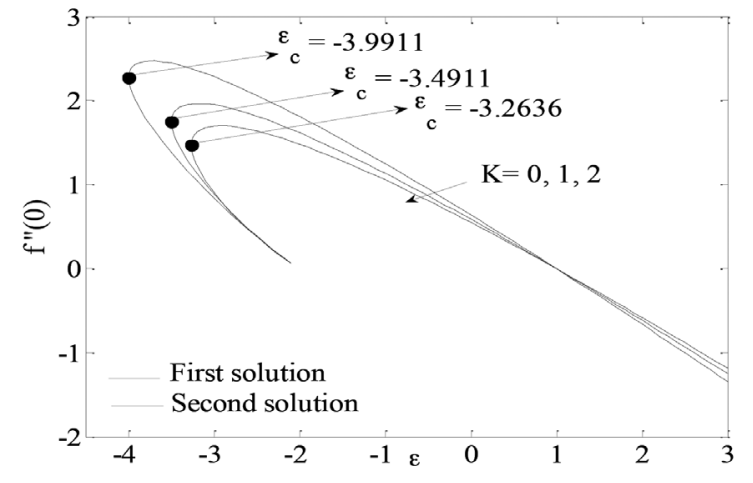

FIGURE 2. Skin friction coefficient $f^{\prime \prime}(0)$ for different values of $K$ when $m=0.5, M=1, \lambda=1$

existence of the magnetic, slip and material parameters in the present study. These parameters could enlarge the range of solutions, which delays the flow separation. The solution exists for $\varepsilon \geq \varepsilon_{c}$, where the first and second solutions bifurcate at $\varepsilon=\varepsilon_{c}$. Dual solutions exist for a certain range of the shrinking strength $\varepsilon<0$. For the stretching case, solutions are possible for all values of $\varepsilon$.

Figure 3 manifests the couple stress $h^{\prime}(0)$ for different values of micropolar parameter $K$. The couple stress relates to the gradient of rotational speed of a particle on the surface. For the shrinking plate, the couple stress $h^{\prime}(0)$ also decreases but it increases for the stretching plate, in absolute sense as the parameter $K$ increases. It means, as $K$ increases, the micropolarity of the fluid slowly vanishes on the shrinking plate as the plate is shrunk with higher ratio, but the micropolarity increases when the plate is stretched strongly.

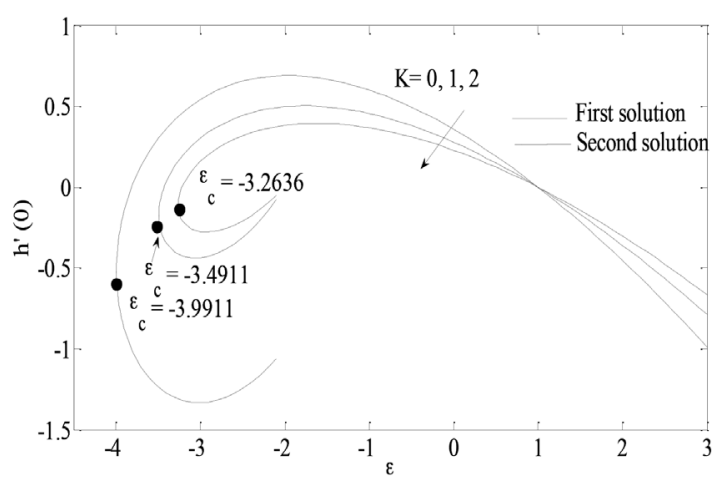

FIGURE 3. Couple stress $h^{\prime}(0)$ for different values of $K$ when $m=0.5, M=1, \lambda=1$

There is a pronounced sign where the values of the surface shear stress $f^{\prime \prime}(0)$ and the couple stress $h^{\prime}(0)$ are zero specifically when the velocity of both plate and fluid are equal, i.e $\varepsilon=1$. Physically, zero surface shear stress is due to the fluid and the solid surface move with the same velocity, and thus there is no friction at the fluid-solid interface. While, when the couple stress is zero, it may be attributed to the non-effect of micro-structure which caused the particle near the surface unable to rotate in which the gradient of rotation is zero. Thus, the flow reduces to the viscous or Newtonion fluid where the flow field is unaffected by the microstructure of the fluid. The range of $\varepsilon$ for which the solution exists decreases as the micropolar parameter $K$ increases.

Figures 4 and 5 illustrate the behaviors of the surface shear stress $f^{\prime \prime}(0)$ and the couple stress $h^{\prime}(0)$ for various values of slip parameter, $\lambda=0,1,3$, against the velocity ratio parameter $\varepsilon$. The range of $\varepsilon$ for which the solution exists increases as the slip parameter $\lambda$ increases. This is due to the slip effect at the boundary which ease the flow on the surface that consequently delays the boundary layer separation. The boundary layer separated from the surface at $\varepsilon=\varepsilon_{c}$, beyond which no solution is in existence. These values of $\varepsilon_{c}$ are stated in Figures 4 and 5, for different values of $\lambda$.

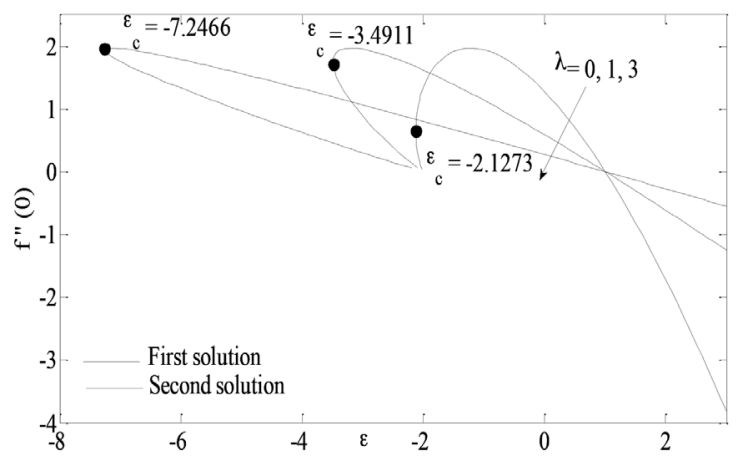

FIGURE 4. Skin friction coefficient $f^{\prime \prime}(0)$ for different values of $\lambda$ when $m=0.5, M=1, K=1$

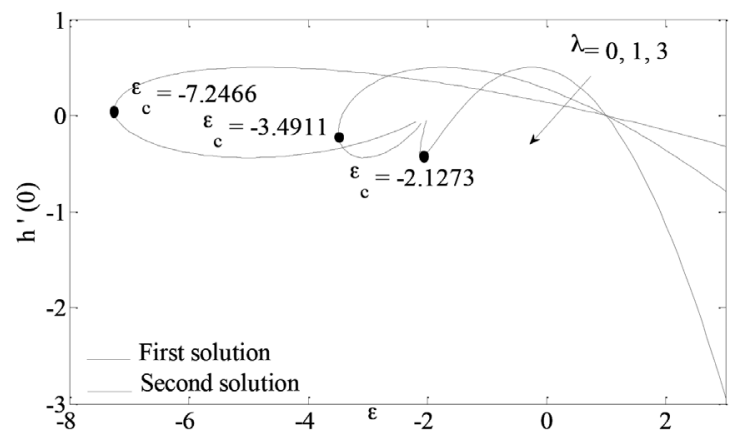

FIGURE 5. Couple stress $h^{\prime}(0)$ for different values of $\lambda$ when $m=0.5, M=1, K=1$

Figures 6 and 7 show the influence of magnetic field $M$ on the skin friction coefficient $f^{\prime \prime}(0)$ and the couple stress $h^{\prime}(0)$ when $m=0.5, \lambda=1$ and $K=1$. Both figures show the solution domain become wider as the magnetic field increases. Solutions for the shrinking case are possible up to the critical values $\varepsilon_{c}$ Dual solutions are obtained for a certain range of $\varepsilon$. For stretching case, solutions are possible for all values of $\varepsilon$ and the solutions are unique. The skin friction coefficient and the couple stress increase as the 


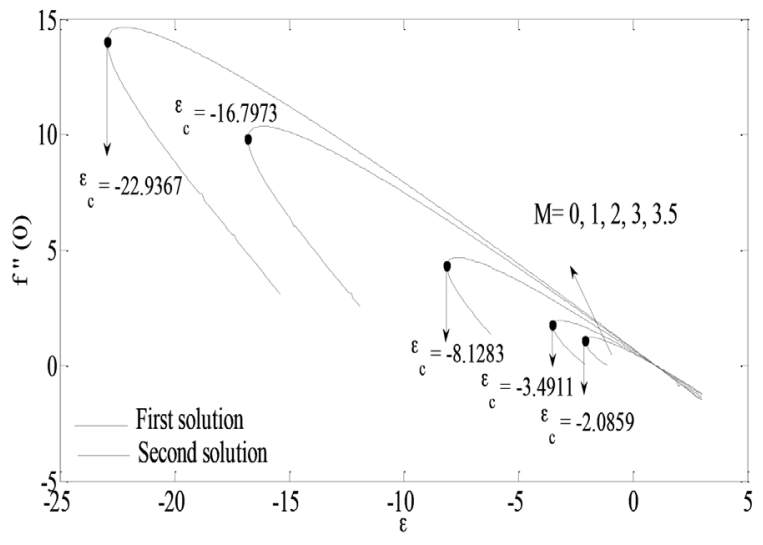

FIGURE 6. Skin friction coefficient $f^{\prime \prime}(\eta)$ for different values of $M$ when $m=0.5, \lambda=1, K=1$

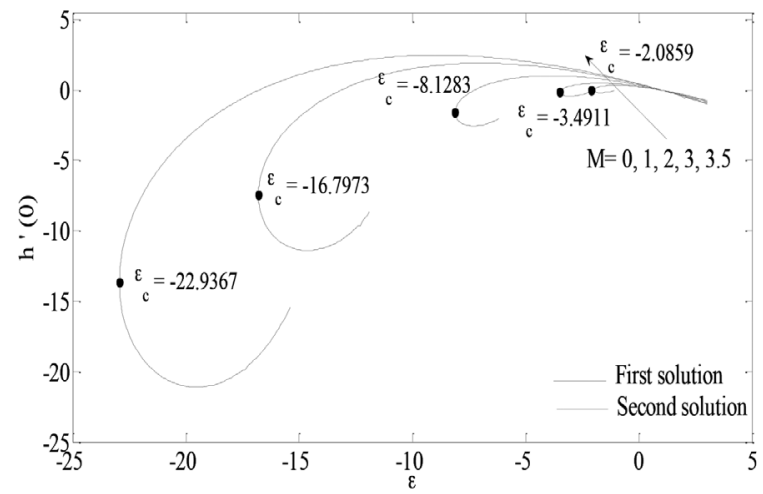

FIGURE 7. Couple stress $h^{\prime}(0)$ for different values of $M$ when $m=0.5, \lambda=1, K=1$

magnetic parameter increases. The presence of magnetic field exerts viscous drag forces on the flow field which results in the deceleration of the fluid's momentum and thus increase the skin coefficient on the surface. This due to the Lorentz force that produces a resistive force towards the flow which causes the slowing movement of the fluid. Moreover, the high intensity of magnetic field could also enhance the rotation the the particles on the shrinking plate. However, it diminishes as the plate is shrunk strongly.

The linear velocity $f^{\prime}(\eta)$ and the angular velocity $h(\eta)$ profiles bounded by the boundary layer for different values of the micropolar parameter $K$ and slip parameter $\lambda$ are denoted in Figures 8-11. Both parameters significantly influence the linear velocity and the angular velocity profiles. The linear velocity distribution in Figure 8 reduces with an increase in $K$ for both first and second solutions even though the distribution increases at the beginning for the second solution. This results in the increase of the boundary layer thickness for both first and second solutions.

Meanwhile, the angular velocity in Figure 9 decreases with the increment of $K$ for the first solution even though there is an increase in the gyration on the surface initially. In other words, the fluid moves rapidly on the surface

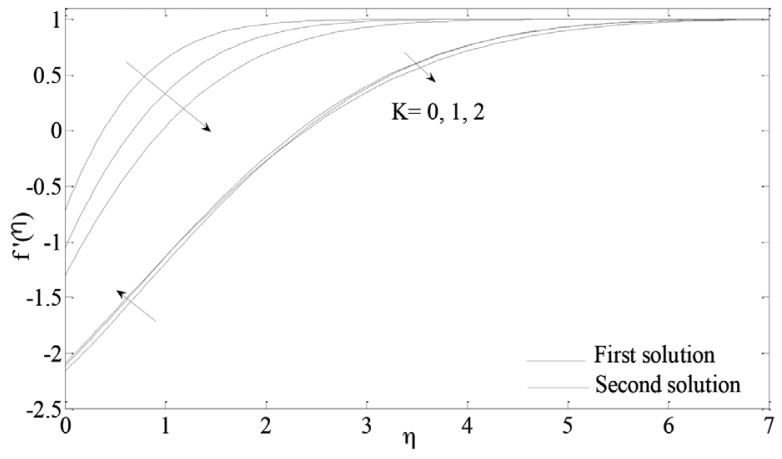

FIGURE 8 . Velocity profiles $f^{\prime \prime}(\eta)$ for different values of micropolar parameter $K$ when $\lambda=1, m=0.5, M=1$ and $\varepsilon=-3$

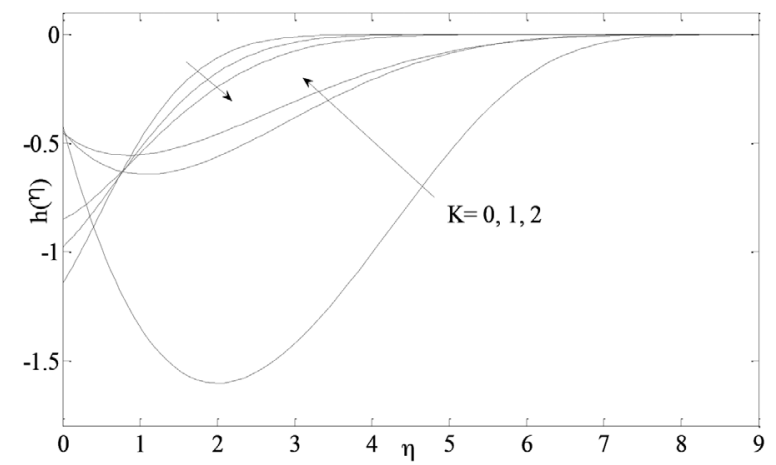

FIGURE 9. Angular velocity profiles $h(\eta)$ for different values of micropolar parameter $K$ when $\lambda=1, m=0.5, M=1$ and $\varepsilon=-3$

in a whirling motion. Moreover, there is a point where the angular velocity profiles intersect near the surface (approximately $\eta=1$ ) for the first solution. This indicates that this layer presents a transition state after which the opposite effect, i.e. $|h(\eta)|$ increases with an increasing $K$ till the free stream state is attained. It shows that near the solid surface, the effect of microrotation is more pronounced for the first solution compared to that of the second solution. For the second solution, the angular velocity continuously increases with $K$ in the boundary layer. Both profiles presented in Figures 8 and 9 satisfy the far field boundary conditions (11) asymptotically, i.e. $f^{\prime}(\eta) \rightarrow 1$ and $h(\eta) \rightarrow 0$ as $\eta \rightarrow \infty$.

The influence of the slip parameter $\lambda$ on the velocity $f^{\prime}(\eta)$ and the angular velocity $h(\eta)$ in the boundary layer when $K=1, m=0.5$ and $M=1$ for the shrinking case with $\varepsilon=-3$ are depicted in Figures 10 and 11, respectively. Both figures clearly noted that the boundary layer thickness decreases as the value of $\lambda$ increases for the first solutions and opposite observations are seen for the second solutions. For the first solutions, the effect of slip parameter is opposite to that of material parameter $K$ in Figures 8 and 9 which both velocities increase with $\lambda$. For the second solutions, the velocity is less dominant near the surface as revealed in Figures 8 and 9 compared to those of the second solutions in Figures 10 and 11. Near the boundary, the angular velocity $h(0)$ is lower, in absolute sense, on 


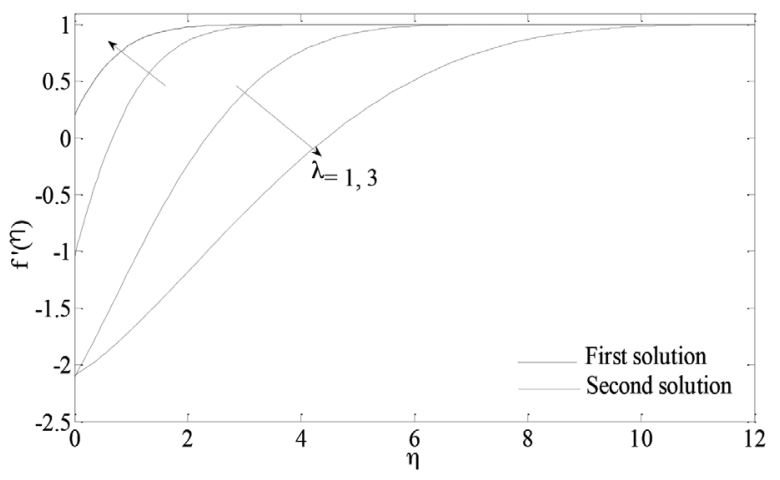

FIGURE 10 . Velocity profiles $f^{\prime \prime}(\eta)$ for different values of slip parameter $\lambda$ when $K=1, m=0.5, M=1$ and $\varepsilon=-3$

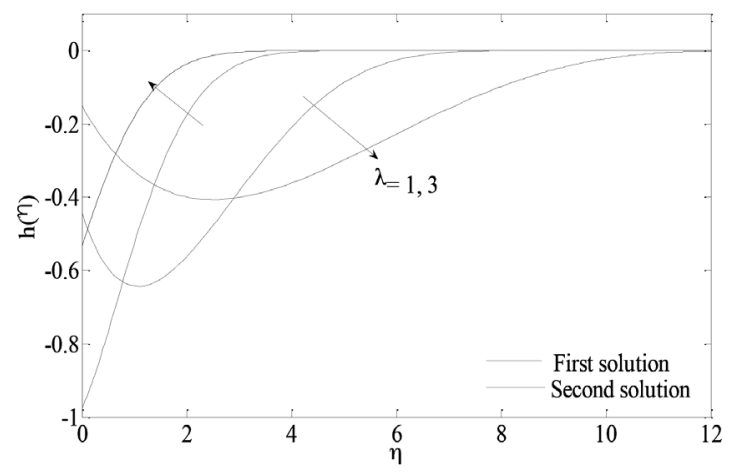

FIGURE 11 . Angular velocity profiles $h(\eta)$ for different values of slip parameter $\lambda$ when $K=1, m=0.5, M=1$ and $\varepsilon=-3$

the high slippery surface. Then, the reverse is seen for the second solution, far from the surface. This shows a sign of instability of the second solution.

In the present paper, dual solutions are identified and they exist when the stretching/shrinking parameter $\varepsilon<-2$. A stability analysis is performed to determine which one of the solutions is stable and which one is not. Similar analyses were done by Awaludin et al. (2016), Roşca and Pop (2013) and Weidman et al. (2016) where they found that the first solution is stable while the second solution is unstable. We find the eigenvalues $\gamma$ in (18). The smallest eigenvalue $\gamma$ for some values of $K$ and $\varepsilon$ are shown in Table 3 when $\lambda=1, m=0.5$ and $M=1$. Apparently, the positive values of $\gamma$ belong to the first solutions whilst the negative values of $\gamma$ are for the second solutions. Therefore, the first solution is stable while the second solution is unstable. It is observed that as $\varepsilon$ approaches critical value $\varepsilon_{c}$, the smallest eigenvalue is leading to zero and whenever $\varepsilon$ is far from $\varepsilon_{c}$, the values of the smallest eigenvalue become larger, in absolute sense. This shows that the transitions from positive (stable) to negative (unstable) of $\gamma$ occur at the turning points of the curves. These values of $\varepsilon_{c}$ are presented in Figures 2-7.

\section{CONCLUSION}

The present paper studied the problem of MHD twodimensional stagnation point flow over a stretching/ shrinking surface immersed in a micropolar fluid with slip effect at the boundary. The governing boundary layer equations were solved numerically using the boundary value problem solver, bvp4c, in Matlab software. Numerical solutions were presented for material parameter $m=0.5$ which indicates the weak concentration and the magnetic parameter $M=1$ with the combination effects of the stretching/shrinking parameter $\varepsilon$, slip parameter $\lambda$ and micropolar parameter $K$. The stability analysis showed that there is an initial decay of disturbance for the first solution, while the second solution showed an initial growth of disturbance, indicated that the first solution is stable and thus physically reliable, while the second solution is not. A prominent result was found for the first solution, which is, an increase in the micropolar parameter $K$ led to a decrease

TABLE 3. Smallest eigenvalues at several values of $K$ when $\lambda=1, m=0.5, M=1$

\begin{tabular}{cccc}
\hline$K$ & $\varepsilon$ & Upper branch & Lower branch \\
\hline 0 & -3.0 & 2.1489 & -1.8333 \\
& -3.2 & 1.9216 & -1.6779 \\
& -3.4 & 1.6610 & -1.4845 \\
& -3.9 & 0.6456 & -0.6201 \\
& -3.95 & 0.4317 & -0.4203 \\
1 & -3.99 & 0.0697 & -0.0694 \\
& -3.0 & 1.5999 & -1.4152 \\
& -3.2 & 1.2282 & -1.1224 \\
& -3.4 & 0.6813 & -0.6492 \\
& -3.45 & 0.4552 & -0.4409 \\
& -3.49 & 0.0734 & -0.0730 \\
& -3.0 & 1.2229 & -1.1096 \\
& -3.2 & 0.5940 & -0.5677 \\
& -3.25 & 0.2727 & -0.2670 \\
\hline
\end{tabular}


of the skin friction coefficient $f^{\prime \prime}(0)$ and the couple stress $h^{\prime}(0)$, in absolute sense. Similar behavior was seen for the slip effects at the boundary on the skin friction coefficient and the couple stress. These solutions may be applicable to flow of suspension solution over a flat plate.

\section{ACKNOWLEDGEMENTS}

The authors are indebted to the referees for their valuable comments and suggestions, which led to the improvement of the paper. The financial supports received from the Universiti Kebangsaan Malaysia (Project Code: GUP2018-153) and the Ministry of Education, Malaysia are gratefully acknowledged. The work of Ioan Pop has been supported by the grant PN-III-P4-ID-PCE-2016-0036, 266 UEFISCDI, Romania.

\section{REFERENCES}

Abbas, N., Saleem, S., Nadeem, S., Alderremy, A.A. \& Khan, A.U. 2018. On stagnation point flow of a micro polar nanofluid past a circular cylinder with velocity and thermal slip. Result in Physics 9: 1224-1232.

Ahmadi, G. 1976. Self-similar solution of incompressible micropolar boundary layer flow over a semi-infinite plate. International Journal of Engineering Science 14: 639-646.

Aman, F., Ishak, A. \& Pop, I. 2013a. MHD stagnation point flow of a micropolar fluid toward a vertical plate with a convective surface boundary condition. Bulletin of the Malaysian Mathematical Sciences Society 36: 865-879.

Aman, F., Ishak, A. \& Pop, I. 2013b. Magnetohydrodynamic stagnation-point flow towards a stretching/shrinking sheet with slip effects. International Communications in Heat and Mass Transfer 47: 68-72.

Andersson, H.I. 1995. An exact solution of the Navier-Stokes equations for magnetohydrodynamic flow. Acta Mechanica 113: 241-244.

Awaludin, I.S., Weidman, P.D. \& Ishak, A. 2016. Stability analysis of stagnation-point flow over a stretching/shrinking sheet. AIP Advances 6: 045308.

Basir, M.F.M., Uddin, M.J. \& Ismail, A.I.M. 2017. Unsteady magnetoconvective flow of bionanofluid with zero mass flux boundary condition. Sains Malaysiana 46(2): 327-333.

Borrelli, A., Giantesio, G. \& Patria, M.C. 2015. MHD orthogonal stagnation-point flow of a micropolar fluid with the magnetic field parallel to the velocity at infinity. Applied Mathematics and Computation 264: 44-60.

Chakrabarti, A. \& Gupta, A.S. 1979. Hydromagnetic flow and heat transfer over a stretching sheet. Quarterly of Applied Mathematics 37: 73-78.

Chiam, T.C. 1995. Hydromagnetic flow over a surface stretching with a power-law velocity. International Journal of Engineering Science 33: 429-435.

Das, K. 2012. Slip effects on MHD mixed convection stagnation point flow of a micropolar fluid towards a shrinking vertical sheet. Computers \& Mathematics with Applications 63: 255-267.

Eringen, A.C. 1966. Theory of micropolar fluids. Journal of Mathematics and Mechanics 16: 1-18.

Fisher, E.G. 1976. Extrusion of Plastics. New York: Wiley.

Hafidzuddin, E.H., Nazar, R., Arifin, N.M. \& Pop, I. 2015. Numerical solutions of boundary layer flow over an exponentially stretching/shrinking sheet with generalized slip velocity. International Journal of Mathematical, Computation, Physical, Electrical and Computer Engineering 9(4): 240-245.

Hiemenz, K. 1911. Die Grenzschicht an einem in den gleichförmigen Flüssigkeitsstrom eingetauchten geraden Kreiszylinder. Dinglers Polytech Journal 326: 321-324.

Imran, M.A., Riaz, M.B., Shah, N.A. \& Zafar, A.A. 2018. Boundary layer flow of MHD generalized Maxwell fluid over an exponentially accelerated infinite vertical surface with slip and Newtonian heating at the boundary. Results in Physics 8: 1061-1067.

Ishak, A. 2011. MHD boundary layer flow due to an exponentially stretching sheet with radiation effect. Sains Malaysiana 40(4): 391-395.

Ishak, A., Lok, Y.Y. \& Pop, I. 2010. Stagnation-point flow over a shrinking sheet in a micropolar fluid. Chemical Engineering Communications 197: 1417-1427.

Ishak, A., Nazar, R. \& Pop, I. 2009. Dual solutions in mixed convection boundary layer flow of micropolar fluids. Communications in Nonlinear Science and Numerical Simulation 14: 1324-1333.

Ishak, A., Nazar, R. \& Pop, I. 2008. MHD boundary-layer flow due to a moving extensible surface. Journal of Engineering Mathematics 62: 23-33.

Jena, S.K. \& Mathur, M.N. 1981. Similarity solutions for laminar free convection flow of a thermomicropolar fluid past a non-isothermal vertical flat plate. International Journal of Engineering Science 19: 1431-1439.

Peddieson, J.J. 1972. An application of the micropolar fluid model to the calculation of a turbulent shear flow. International Journal of Engineering Science 10: 23-32.

Lok, Y.Y., Amin, N., Campean, D. \& Pop, I. 2005. Steady mixed convection flow of a micropolar fluid near the stagnation point on a vertical surface. International Journal of Numerical Methods for Heat \& Fluid Flow 15(7): 654-670.

Malvandi, A., Hedayati, F. \& Ganji, D.D. 2014. Slip effects on unsteady stagnation point flow of a nanofluid over a stretching sheet. Powder Technology 253: 377-384.

Mat Yasin, M.H., Ishak, A. \& Pop, I. 2017. Boundary layer flow and heat transfer past a permeable shrinking surface embedded in a porous medium with a second-order slip: A stability analysis. Applied Thermal Engineering 115: 1407-1411.

Meeten, G.H. 2004. Squeeze flow of soft solids between rough surfaces. Rheology Acta 43: 6-16.

Merkin, J.H. 1985. On dual solutions occurring in mixed convection in a porous medium. Journal of Engineering Mathematics 20: 171-179.

Mooney, M. 1931. Explicit formulas for slip and fluidity. Journal of Rheology (1929-1932) 2(2) : 210-222.

Nair, K.A. \& Sameen, A. 2015. Experimental study of slip flow at the fluid-porous interface in a boundary layer flow. Procedia IUTAM 15: 293-299.

Najib, N., Bachok, N., Arifin, N.M. \& Ishak, A. 2014. Stagnation point flow and mass transfer with chemical reaction past a stretching/shrinking cylinder. Scientific Report 4(4178): 1-7.

Nazar, R., Amin, N., Filip, D. \& Pop, I. 2004. Stagnation point flow of a micropolar fluid towards a stretching sheet. International Journal of Non-Linear Mechanics 39: 12271235.

Papautsky, I., Brazzle, J., Ameel, T. \& Frazier, A.B. 1999. Laminar fluid behavior in microchannels using micropolar 
fluid theory. Sensors and Actuators A: Physical 73(1-2) : 101-108.

Rahmati,A.R.,Akbari, O.A., Marzban, A., Toghraie, D., Karimi, R. \& Pourfattah, F. 2018. Simultaneous investigations the effects of non-Newtonian nanofluid flow in different volume fractions of solid nanoparticles with slip and no-slip boundary conditions. Thermal Science and Engineering Progress 5: 263-277.

Roşca, N.C. \& Pop, I. 2013. Mixed convection stagnation point flow past a vertical flat plate with a second order slip: Heat flux case. International Journal of Heat and Mass Transfer 65: 102-109.

Sajid, M., Mahmood, K. \& Abbas, Z. 2012. Axisymmetric stagnation-point flow with a general slip boundary condition over a lubricated surface. Chinese Physics Letters 29(2): 0247021-0247024.

Shercliff, J.A. 1965. A Textbook of Magnetohydrodynamics. Oxford: Pergamon Press.

Shu, J.J. \& Lee, J.S. 2008. Fundamental solutions for micropolar fluids. Journal of Engineering Mathematics 61(1) : 69-79.

Tretheway, D.C. \& Meinhart, C.D. 2002. Apparent fluid slip at hydrophobic microchannel walls. Physics of Fluids 14(3) : L9-L12.

Uddin, M.J., Alginahi, Y., Beg, O.A. \& Kabir, M.N. 2016. Numerical solutions for gyrotactic bioconvection in nanofluid-saturated porous media with Stefan blowing and multiple slip effects. Computers and Mathematics with Applications 72(10): 2562-2581.

Wang C.Y. 2008. Stagnation flow towards a shrinking sheet. International Journal of Non-Linear Mechanics 43: 377-382.

Wang, C.Y. 2003. Stagnation flows with slip: Exact solutions of the Navier-Stokes equations. Zeitschrift für Angewandte Mathematik und Physik (ZAMP) 54(1): 184-189.

Weidman, P. 2016. Axisymmetric rotational stagnation point flow impinging on a radially stretching sheet. International Journal of Non-Linear Mechanics 82: 1-5.

Yacob, N.A., Ishak, A. \& Pop, I. 2011. Melting heat transfer in boundary layer stagnation-point flow towards a stretching/ shrinking sheet in a micropolar fluid. Computers and Fluids 47(1): 16-21.
Yoshimura, A. \& Prud'homme, R.K. 1988. Wall slip corrections for couette and parallel disk viscometers. Journal of Rheology 32: 53-67.

Zaimi, K., Ishak, A. \& Pop, I. 2014. Boundary layer flow and heat transfer over a nonlinearly permeable stretching/shrinking sheet in a nanofluid. Scientific Reports 4(4404): 1-8.

Siti Khuzaimah Soid

Faculty of Computer and Mathematical Sciences

Universiti Teknologi MARA

40450 UiTM Shah Alam

Selangor Darul Ehsan

Malaysia

Anuar Ishak*

School of Mathematical Sciences

Faculty of Science and Technology

Universiti Kebangsaan Malaysia

43600 UKM Bangi

Selangor Darul Ehsan

Malaysia

Ioan Pop

Department of Mathematics

Babeș-Bolyai University

400084 Cluj-Napoca

Romania

*Corresponding author; email: anuar_mi@ukm.edu.my

Received: 15 January 2018

Accepted: 20 July 2018 